\title{
Locating Transnational Memory
}

\section{Jenny Wüstenberg ${ }^{1}$}

Published online: 18 July 2019

(C) Springer Science+Business Media, LLC, part of Springer Nature 2019

Keywords Transnational memory $\cdot$ Memory studies $\cdot$ Locatedness $\cdot$ Place/space $\cdot$ Mechanism

The conventional understanding of public remembrance has been contained within the boundaries of the nation, the state, or the local community. With the arrival of what Astrid Erll has called the "third phase" of memory studies (Erll 2011, 4), commemoration is now analyzed in terms of its "unbounded" quality and is "considered a fluid and flexible affair" (Bond et al. 2016, 1). Memory straddles established divides, it moves and travels, and it is actively transformed in the process. And yet, a significant part of what continues to fascinate scholars about memory is its groundedness in concrete locations. The possibility of "visiting" one's object of research, of interacting with those who experience memory as the intended (or unintended) audience, and witnessing transnationality "up close" is what draws scholarly inquiry. So how can we best connect the obvious significance of the local to the reality of transnational remembering?

This special issue addresses this tension between the production of remembrance through transnational processes and its grounding in concrete locations. Underlining the presence of transnationality in commemoration, this volume examines how historical events and experiences that transcend national boundaries, global norms, experiences of mobility, or awareness of the "world out there" are manifested in particular realms of memory. The contributors come from different disciplinary backgrounds (literary studies, sociology, political science, history, peace, and conflict studies) and focus on memory spaces in a diverse set of geographies - including in Australia, Austria, Bosnia-Herzegovina, Norway, the Philippines, South Africa, and the USA. They also investigate sites dedicated to different and complex pasts that are transnationalized through various mechanisms and with different results for local remembrance. ${ }^{1}$

\footnotetext{
${ }^{1}$ I would like to stress the collegial experience that has made this volume possible. First and foremost, I thank the authors of this volume, who delivered excellent and thought-provoking articles within a short time frame. I have learnt a great deal from their expertise. Second, I thank the 14 reviewers, who delivered their feedback on time and in a productive spirit. Last, I thank Patrick Baert, the editor of the International Journal of Politics, Culture, and Society, who reacted enthusiastically to my proposal, agreed to publish it without the now common multiyear waiting period, and supported the special issue in an unbureaucratic fashion.
}

Jenny Wüstenberg

jwustenb@yorku.ca 
The diversity of these cases is intentional and my goal in assembling them is twofold. First, given the extraordinary vibrancy of the new field of "transnational memory studies," we bring together state-of-the-art empirical research in order to allow the articles to productively speak to each other and to showcase the complexity of transnational remembering. Readers will no doubt find numerous methodological, empirical, and theoretical insights in these pieces that can provide fruitful impulses for their own work. Second, notwithstanding their diversity, the contributions raise (and seek to answer) a set of common questions, including the following: How is transnational remembering "done" in "real" places? Who are the individuals and institutions that are driving transnationalization? Through which local (and non-local) practices does the process of transnationalization occur? Is transnationality a characteristic that is experienced evenly across time and by different actors? And does transnational remembering result in specific normative frameworks, esthetics, or tropes? By addressing these questions, the authors help to specify how the notion of a "transnational memory space," which remains underdeveloped and abstract, works in practice. Importantly, the special issue demonstrates not simply the presence of transnationality in memorial sites, but examines closely the processes underpinning its production, its outcomes, and its limitations.

A short overview of the articles in this volume will serve as a backdrop to the analysis that follows - linking them to shared ideas about locality and transnationalism.

Annika Bjorkdahl and Stefanie Kappler explain the transnational commemoration of statedriven violence by comparing the Robben Island Memorial in South Africa and the Galerija 11/07/95 in Bosnia Herzegovina. They understand these sites as situated both in global normative discourses of "never again" and within the global political economy of "dark tourism." As such, the actors in charge of these memorials strategically engage in mechanisms of commercialization and professionalization in their efforts to translate local memory for global audiences.

Rosanne Kennedy and Sulamith Graefenstein examine the Sydney Jewish Museum, as well as the work of the Australian-Aboriginal artist Judy Watson, to understand the multidirectional and transnational reverberations of the Holocaust and colonial violence. The authors first discuss the national-political context of Holocaust memory in Australia and juxtapose it to the efforts of the community-based museum to make Holocaust memory productive of a public discussion about human rights violations. Kennedy and Graefenstein (2019) then turn to analyze two works of Judy Watson as a way to articulate a "feminist decolonial approach to memory that is both located and transnational". In showcasing two different instances of memory politics in Australia, the authors seek to further develop the multidirectional mode of memory studies.

Jocelyn Martin traces the process of shifting the corpse of former President Ferdinand Marcos from exile to the Heroes' Cemetery in the Philippine capital Manila, thereby highlighting the meaning of exile and local politics for the transformation of this memorial site. Squarely placing her analysis in the current movement-oriented paradigm of memory studies, Martin argues that it is precisely such an approach that allows us to understand the powerful actors and structures that continue to shape public remembering and prevent that mnemonic justice is done to victims of dictatorial violence.

Peter Pirker, Johannes Kramer, and Mathias Lichtenwagner discuss Holocaust commemoration in Vienna where narratives of national victimization and innocence also long dominated. Based on in-depth analysis of three recent mnemonic projects, as well as an exhaustive survey of Viennese memorial sites, the authors argue that Holocaust remembrance transcends local boundaries through the mechanisms of synthesizing and spacing. They provide a detailed 
analysis of the actors and practices involved in each case, and argue that though local considerations may at first sight seem to shape these cases, their interaction with transnational policy networks, as well as global normative debates, are in fact just as important.

Anette Storeide traces the transformation of the commemoration of WWII in Norway, where national memorial institutions such as the "Norwegian Homefront Museum" were long dominated by what has been called a "national consensus syndrome," in which the German occupation and Norwegian resistance dominated, while any memory of complicity in the Holocaust or the fate of Norwegian Jews was sidelined. Storeide closely analyzes the domestic processes that began to change this narrative and the ways in which they were shaped by transnational mnemonic agency, the changing global climate with respect to restitution and recognition, and the adoption of commemorative forms developed in other countries.

One central question ties together all the articles: how is transnational remembering made local or grounded in concrete memory sites and how are such sites made transnational? We might expect to see a fundamental tension between memory actors and audiences that view sites as grounded in local meaning versus those that view their meaning through a transnational lens. My purpose in this introduction is to situate this question and its implicit frictions in some of the recent literature of the "third phase" of memory studies, as well as in the scholarship on spatial politics. Drawing on these sources for insight and highlighting key points made by the authors of this volume, I argue that the relational nature of place and space, as well as the concept of scale, can help us think through how the local and transnational are intermeshed and what this means for the outcomes of mnemonic practice. As each of the articles demonstrates in different ways, the evocation of transnational memory does not eclipse locality, but it does have transformative potential, with both positive and negative outcomes. I conclude this introduction by distilling the most salient mechanisms that are employed by memory actors to transnationalize commemoration, drawing on the cases examined in this volume.

\section{Location in Memory Studies}

Transcultural memory as a research perspective, according to Astrid Erll, incorporates scholarship that is "directed towards mnemonic processes unfolding across and beyond cultures. It means transcending the borders of traditional 'cultural memory studies' by looking beyond established research assumptions, objects and methodologies” (Erll 2011, 9). Similarly, Lucy Bond, Stef Craps, and Pieter Vermeulen argue that memory "is presently conceptualized as something that does not stay put, but circulates, migrates, travels; it is more and more perceived as a process" (Bond et al. 2016, 1). With extraordinary speed, this new research perspective has produced a canon that includes the work of Daniel Levy and Natan Sznaider, Ann Rigney, Astrid Erll, Michael Rothberg, Rosanne Kennedy, and others. These interventions are empirically grounded, highly complex, and none of them simplistically claim that memories move irrespective of established borders or that powerful entities have no influence on their production and circulation. Nevertheless, in terms of its theoretical framing, memory studies as a field seem to have shifted attention away from "locations" to notions of mobility and movements. In so doing, it has called into question any remaining assumptions about the boundedness of remembrance - by the nation-state in particular.

At the same time, location remains important for memory scholars. Indeed, as Susannah Radstone has pointed out, researchers are currently producing "rich and detailed analyses of the resonance, meaning and affectivity of highly specific and located processes, acts and 
events of memory and forgetting" while calling for a "transcultural lens" (Radstone 2011, 114). Radstone goes on to caution that not all memory is mobile and fluid:

Some memories get stuck and will not be easily forgotten. Without attending to the locatedness of memory, as well as its movements, theories of transnational and transcultural memory, with their focus on memory's high-speed (often digital) travel around the globe, risk eliding such memories from view, precisely because of their locatedness and immobility. They therefore risk producing a self-fulfilling theory by telling the story of only those memories that - for whatever reason - do move, or appear to move, between locations (Radstone 2011, 115).

Similarly, Emily Keightley and Michael Pickering argue that the "relationship between spatial dislocation and memory has, in the last decade, emerged as a preoccupation of memory studies research" (Keightley and Pickering 2017, 119) and that such an approach brings the risk of abstracting memory from the creative social practices within which it is embedded (ibid., 120).

This article takes this apparent contradiction between the "dislocatedness" of the transcultural research paradigm (as an umbrella term for the third phase of memory studies) and the practice of memory scholarship as a point of departure and probes how spatial concepts can help resolve the incongruity. For starters, there is nothing like a clean division between these competing visions. In fact, partly because such luminaries of memory studies as Maurice Halbwachs and Pierre Nora laid the groundwork concerning the spatial characteristics of social remembering, notions of place, space, landscape, and territory are already a central component of the memory literature. Moreover, despite their reputation for being concerned primarily with dislocation, movement, or cross-border diffusion, newer memory research actually has quite a bit to say about questions of location. This is the case in particular for those scholars who adopt the terminology of "transnational" memory - probably because this term necessitates grappling with the roles of the state and the nation. Barbara Tornquist-Plewa has made a useful distinction between transnational memories as those shared across borders, while transcultural memories denote more specifically a kind of hybridization of memories that not only crosses cultural borders but "enables the imagining of new communities and new types of belonging" (Tornquist-Plewa 2018, 302). Törnquist-Plewa argues that transnational remembering may carry the potential for transcultural memory, but it does not necessitate it. Put differently, "transnational" is about the relationship between multiple localities of memory and "transcultural" is about their blending. This broad understanding of the transnational is applied in this special issue to analyze a variety of modes of cross-border memory without suggesting necessary outcomes.

The key innovation of the third phase of memory studies is to shift away from static notions of memorial sites to understanding the locatedness of remembering through relational conceptualizations of place and space. Paradoxically, the "spatial turn" in memory studies may be seen as a reaction to the ubiquitous influence of Nora's research program on sites of memory, because in it, the lieux de mémoire were regarded as relatively stagnant and durable (though Nora applied the concept broadly to include more than just physical places.) With the "spatial turn," conceptualizations of space no longer refer to territoriality or containers of traditions, but rather the social production of space through multi-layered and contradictory processes, as well as the particularity and malleability of spatial practices (Bachmann-Medick 2009, 288-289). Despite the fact that Nora's approach has been applied widely, not only to survey national memorial sites, but also to transnational sites (for example den Boer et al. 2011; Hahn and Traba 2013), scholars have 
criticized the "lieu de mémoire" for its tendency to canonize and homogenize national memory (Berger and Seiffert 2014, 33). Stefan Berger and Joana Seiffert have gone so far to call on us to abandon the concept of "Erinnerungsort" (place of memory) in favor of concepts such as "space" and "landscape," as both allow for a more fluid, context-dependent, and processual understanding of remembering (Berger and Seiffert 2014, 35).

However, I would like to suggest that replacing place with space (or similar terms) is not going to be useful. It is precisely the tension and differentiation between the terms "site" or "place" and "space" and "landscape" that we need to capture when we analyze dynamics of transnational memory. This is very much the spirit of Pirker, Kramer, and Lichtenwagner's work on Viennese memorial sites and their relational creation through "synthesis" and "spacing" as active notions of linking physical locations to mental and social spaces. While actors may remember locally, transnationality is manifested in the performances and mental connections made in the process. And while some places are actively "made transnational" through such practices of linking, other memorial sites are transnational from the outset by virtue of remembering a past that was itself transnational, such as the struggle against apartheid or the mass-mediated genocide in Bosnia. Björkdahl and Kappler (2019) call these diagnostic sites "that hold in place collective memories that have a transnational character as they speak to globalized memory discourses". While such sites might be expected to be transnational "automatically," they in fact do not require any less agency than those places where the past appears more localized. As Bjrkdahl and Kappler show, these sites too rely on active practices of place-making and linking to transnational reference points, to "hold in place" their transnational character. Kennedy and Graefenstein argue that it is precisely the local embeddedness of memories that enables visitors to link in intelligible ways to transnational memory. Thus, the Sydney Jewish Museum's human rights exhibit multidirectionally connects Holocaust remembrance to a universal human rights discourse via the local memory of colonial violence and discrimination against migrants and others. Transnational memory is made possible only through the pathway of local remembering, because without it, Holocaust memory would remain abstracted and distant for a general audience.

Yi-Fu Tuan, one of the foremost theorists of space, addressed this idea of an interplay between stillness (here: fixing a collective memory) and movement (creating a notion of connected transnational memories). He argued that "the ideas 'space' and 'place' require each other for definition. From the security and stability of place we are aware of the openness, freedom, and threat of space, and vice versa. Furthermore, if we think of space as that which allows movement, then place is pause; each pause in movement makes it possible for location to be transformed into place" (Tuan 1977, 6). With this in mind, one can think of the creation of a memory site as a set of practices of place-making, of an effort to halt movement and to achieve stability, making memory meaningful through a local act of commemoration. Interestingly, Tuan, writing before Nora, had a very similar notion of what memorialization practices signify for societal development. Nora contended that modernity creates societies that lose their mileux de mémoire, that is, remembering as ritual and lived experience. In their stead, modern communities construct lieux de mémoire (Nora 1996). Tuan writes: "Being rooted in a place is a different kind of experience from having and cultivating a 'sense of place.' A truly rooted community may have shrines and monuments, but it is unlikely to have museums and societies for the preservation of the past. The effort to evoke a sense of place and of the past is often deliberate and conscious" (Tuan 1977, 198). Thus, while senses of place must be actively constructed, "place" continues to exist in human experience - and is highly meaningful for identity formation. The creation of "authentic" and "unique" places in 
general - and of memory sites in particular-is fundamental to linking humans through feelings of similarity, as well as excluding "others" from the community (Gupta and Ferguson 1997; Maier 2007). However, as Walter Nicholls and colleagues stress, a place should not be equated with "the local" per se, but rather seen as a location where potentially "geographically extensive" processes meet and operate (Nicholls et al. 2013, 4). In other words, a place can be transnational by virtue of the links and practices that happen there, but agency (memory work) is invested in stabilizing this sense of transnationality in that location.

In an excellent model of how to apply third-phase considerations to seemingly stable sites, Martin analyzes what could be regarded as a quintessential "lieu de mémoire" for the Philippines - the national Heroes Cemetery. She clearly demonstrates that even with a site that is seemingly highly fixed in meaning, transnational and mobile memory practices - here the cross-border shifting of Marcos' corpse through the work of powerful "travel agents" (Marcos' family and the Duterte regime) - punctures the stability of collective memory. Moreover, this place must actively be made "stable" again by halting the volatility introduced by the body's transnational movement. This kind of localizing memory work does not necessarily serve the cause of social justice. In this case, transnational processes in no way result in a memorial site that supports victims of large-scale violence in their quest for recognition. Indeed, several of the contributions in this volume show that the ethical effect of transnationalization of memory is highly uneven.

The result of memory work done in a particular place can deliver different outcomes for different communities - simultaneously grounding its meaning in a locality as well as creating memory links to other, transnational places, and events. One way to think about this would be to turn to Marc Augé, who has theorized place in a way that might be seen as logical extension of Nora's and Tuan's views on the transformation of (memory) places in modernity. He argues that our current era of "supermodernity" has witnessed the creation of "non-places," which are not "relational, or historical, or concerned with identity" and are juxtaposed to "places," which are fundamentally concerned with human relationships and identity (Augé 2008, 63). Augé provides the examples of shopping malls and highways to illustrate what a non-place might look likegeneric, dime-a-dozen, familiar but not meaningful or "authentic." While sites of memory could be seen as "places" par excellence (in Augé's sense) — relational, historical, about identityAugé's theory could help us consider whether processes of transnationalization of memory may lead to sites at which localized identities no longer play a central role and where people do not necessarily meet socially and create communities. Is it possible that actors can create "mnemonic non-places," making them irrelevant to identity-formation by overly transnationalizing themthereby removing them from being grounded and meaningful those who experienced the past that the sites claim to represent (or their ancestors)?

There may be some indication of this sort of tendency in Björkdahl and Kappler's findings. They argue that with the development of a globalized regime of memorialization, there is increasingly a drive to find recognition of past injustice not only through local remembrance but by gaining acknowledgement from transnational audiences. The way to do this is to translate local experiences of violence into a globally intelligible language, via the mechanisms of professionalization and commercialization. This act of translation may come at the price of presenting the past in a simplified manner and distinguishing between victims and perpetrators in a stylized way, rather than addressing nuances and contradictions. Moreover, the force behind such a process of transnationalization may not always or only be the cause of mnemonic justice, but political or economic pressures to do with international legitimacy or viability in the (dark) tourism industry. Thus, those whose past is being memorialized may not 
see themselves represented in sites that have actively been transnationalized. And, such sites may be in danger of losing their local specificity, authenticity, and direct linkage to concrete historical events (as opposed to universalized discourses). Calling them non-places of memory might be an exaggeration, but the idea can help us consider the question of how practices of transnationalization can be squared with practices of meaning-making and the functions of public memory for historical justice and democratization.

Moreover, this extreme scenario raises ethical questions about the meaning of transnationality for memorial sites. Several of the special issue authors find evidence that actors strategically use linkage to transnational narratives or esthetics in order to push local commemoration into a more critical direction. For instance, the non-state Sydney Jewish Museum explicitly intertwines its Holocaust remembrance to universal human rights discourses. Judy Watson's art creates transnational cross-currents in order to bolster decolonized feminist narratives. Vienna's memorial entrepreneurs sought to engrain self-reflective memory and call into question nationalist narratives by using esthetic means developed elsewhere. And the Norwegian city of Trondheim helped to publicize the fate of a 13-year-old victim of the Shoah by referring to her as their "Anne Frank." Such findings support Rothberg's argument that "transnational and transcultural processes can 'unhome' the homogenous conceptions of local and national community" (Rothberg 2014, 129). Maier goes so far as to suggest that there is something inherently anti-progressive about localized commemoration, asking whether the notion of place can ever "be invoked without falling into conservative romanticism and a spurious or dangerous bonding?" (Maier 2007, 76).

However, it is worth reemphasizing here that the contributions in this issue also give cause for skepticism about transnationalism as a uniquely progressive force. The re-interment and reheroization of Marcos' body was made possible by its transnational movement, thus allowing for the reinterpretation of the dictator's legacy. Here, the transnational linkage of the national site works against a progressive working through of the past. In Norway, while transnational mnemonic action has led to more critical memorials, it has not been strong enough to overturn the dominant national narratives. And, as already discussed, the Bosnian and South African examples exhibit tendencies of translation of local experiences for transnational audiences that have problematic effects for the victims those sites ostensibly serve. Pirker, Kramer, and Lichtenwagner suggest not only that transnational memory can be unhelpful for causes many scholars would support, but also is sometimes downright detrimental. In Vienna, those actors seeking to implement a self-critical memory culture worked to undo a transnational notion of pan-German Volksgemeinschaft (i.e., a racist and anti-democratic transnationalism), albeit by juxtaposing another (European) transnational memory as a counterweight. As Anna Cento Bull and Hans Lauge Hansen have contended, such "antagonistic" challenges brought by farright and populist memory actors against the "cosmopolitan" mode of remembering are currently on the rise (Cento Bull and Lauge Hansen 2016).

The central conclusion here is that transnational remembering is normatively neutral in that there is no automatic meaning or purpose attached to it. As is the case with any kind of memory, the transnational(ized) variety is shaped by influential actors and prevailing relationships. As Keightley and Pickering have argued, "memories don't move on their own, they move based on power structures and mediated through institutions" (Keightley and Pickering 2017 , 120). The notion of "scale" as a mode of categorizing the level at which practices of remembrances happen is a useful device to grapple with these power dynamics. Reminiscent of "levels of analysis" (usually individual, state, and systemic levels) in classic international relations theory, the scale concept is explicitly linked to the continued relevance of states, not 
only their ability to shape different scales, but also other actors' ability to challenge this scalemaking capacity. Michael Rothberg explains that "transcultural memory refers to the hybridization produced by the layering of historical legacies that occurs in the traversal of cultural borders, while transnational memory refers to the scales of remembrance that intersect in the crossing of geo-political borders" (Rothberg 2014, 130, italics in original). The advantage of examining commemoration with the aid of scale is that it clearly puts a spotlight on the power of those actors that create borders and hierarchies, particularly the state and inter-state organizations, and entails interrogation of mechanisms of the reification of such hierarchies. As Walter Nicholls, Byron Miller, and Justin Beaumont put it "scale is not a spatiality simply to be 'found' in the political landscape, but rather is actively and relationally produced through struggle" (Nicholls et al. 2013, 9).

Moreover, as the primary promoters of the scale concept in memory studies have argued, "transnationalism allows us to grasp the multi-scalarity of socio-cultural processes and the fundamental 'mutual construction of the local, national and global' in the contemporary world (Glick Schiller 2012, 23); as well as the proximity of the intimate and the global (Pratt and Rosner 2012)" thus breaking up "container thinking" (de Cesari and Rigney 2014, 5, italics in original). The work of Judy Watson exemplifies what it means to understand the intimate and the global as proximate. De Cesari and Rigney thus focus on memory's mobility across borders without losing sight of at which scale(s) it is located. However, Rosanne Kennedy and Maria Nugent, while fruitfully adopting the concept, have also critiqued the idea that a "mutual construction" of the local, national, and global takes place, because this implies "a kind of equality - a certain give and take, or influence, that runs in both directions" (Kennedy and Nugent 2016, 64). Instead, as I argue elsewhere, memory practices that straddle borders are not merely free flowing movements but are often characterized by a distinct directionality of agency that indicates that power is unevenly distributed across scales. In other words, transnational remembering is often not governed by a mechanism of equal exchange but through brokerage of powerful actors, imposition from above, or challenge from below (Wüstenberg forthcoming). In sum, the concept of multi-scalarity helps us consider from a different angle how agency at different levels constructs memory in ways that are necessarily both local and transnational.

Several of the articles in this special issue analyze mnemonic action at different scales and what de Cesari and Rigney call "cross-scale intersectionality" (de Cesari and Rigney 2014, 18) - that is, the ways in which actors and narratives at different scales have an intertwining effect. This is most clearly demonstrated by Pirker, Kramer, and Lichtenwagner (2019), who map out the different scales at which actors operate to shape local memorial sites. Similarly, as Storeide shows, those actors that seek to integrate the commemoration of the fate of Norwegian Jews into the national landscape operate at the local, domestic governmental, international, and global scales, but all of them tap into existing narratives that circulate across scales. However, even though mnemonic norms have thus successfully been diffused to various scales, they lack the power to supersede the national myth of resistance to German occupation and non-involvement in the Holocaust. Ultimately, this myth remains the most meaningful memory for the majority of Norwegians, who may never have heard about how Norway's Jews were deported and murdered. While advocates of Holocaust memory in Norway and elsewhere rightly point to the importance of transnationality, then, it does not always appear to be effective in broad measure. Similarly, in the case of Marcos' reburial, Martin shows how a local site of memory is transformed in meaning and receptiveness to this symbolically powerful body, through politics happening at various scales - most importantly national, but 
also transnational. Interestingly, the corpse's tenure in Hawaii and perpetuation of reverence for Marcos' person and legacy over time enabled its return and reconfiguring of the national cemetery. For Martin, it is precisely the travel in which the body engaged that makes it such an instructive case for memory studies in its third phase, because it shows the processual nature of memory even when it is concerned with national remembering.

The tension and interaction between the local and the transnational can happen organically, but it can also be driven by the organized intentions of memory actors. Björkdahl and Kappler also note that actors at various scales work to make traumatic sites legible to transnational audiences. These include especially memorial staff at the local level, as well as international institutions such as UNESCO and transnationally organized civil society organizations engaged in cross-scale transitional justice and memory work. However, unlike in their previous scholarship, Björkdahl and Kappler (2017) are here most interested in identifying the mechanisms through which transnationalization of local memorials is undertaken. The other contributors to the special issue also point to the techniques and processes through which memorials are transformed into or maintained as locations that are part of a transnational space of memory. Such sites link the materiality of the local to an imagined "world out there" in different ways. It is important to note that this link is not equally obvious to all actors and may not be relevant at all to some. For example, Martin's account of the transnational mobility that made possible Marcos' reinterment may not always be meaningful to a visitor of the national lieu de mémoire, but it is certainly key to understanding how he got there. Similarly, the average Viennese may not know or care whether there are "stumbling blocks" all over Europe and thus may not think of them as transnational memorials. Moreover, as Pirker, Kramer and Lichtenwagner point out, transnationalization of memory is often not an explicit goal of memorial initiators. Instead, transnationalization can be a "side-effect" of practices that emerge from local needs and discussions.

The authors contributing to this special issue pinpoint at least five crucial mechanisms through which transnationalism is evoked or supported at different scales. First, and maybe most ubiquitous, is the mechanism of diffusion of memorial narratives, esthetic practices, and tropes. Diffusion happens because actors adopt, appropriate, represent, synthesize, or space these locally in various ways. Second, commercialization is an outcome of the pressure to make memorial sites profitable - though it is not always based on a "pure" profit motive, but on the wish to save a site from destruction or decay. This mechanism leads to the monetization of the experience of visiting a local memorial site and its integration into a global tourist economy. Closely related is the third mechanism, professionalization, which according to Björkdahl and Kappler means implementing transnationally trending modes of presenting the past, such as interactive or experiential exhibitions and the increased use of modern technologies. This indicates that memorial staff are equipped with knowledge of global memorialization regimes that stretches beyond local circumstances. However, my work on memorial politics in Germany suggests that professionalization is not necessarily a "neutral" strategy of trying to utilize newly developed approaches or to train staff, but rather that state actors use the criterion of professionalism to regulate the memorial landscape according to their interests (Wüstenberg 2017, 286-287). These last two mechanisms both tend to favor a process of homogenization of local memorial sites that may make them more easily legible for global audiences but potentially less authentic and meaningful for locals or stakeholders. Fourth, the mechanism of disruption is used in order to challenge sites and narratives of memory. This is a technique used particularly (but not exclusively) by grassroots memory actors, which links local and transnational memories in a way that subjects especially national narratives to critical 
interrogation. Here, it is not transnational memory per se that is deemed "progressive," but the ability of actors to expose the inconsistencies and hypocrisies present in established memories by contrasting them to those "elsewhere." This is the approach used by the actors studied by Kennedy and Graefenstein, for instance. Notably, however, the transnational human rights paradigm does not automatically bolster a critical memorial approach. As Angela Failler demonstrates, the Canadian Museum for Human Rights - notwithstanding the mandate encapsulated in its name - mostly supports a self-congratulatory narrative of "cozy nationalism" (Failler 2018). Finally, the mechanism of brokerage is clearly evident in the articles. Brokerage means that a key actor connects sites or other actors more directly than before or connects them for the first time (Tilly 2001, 25). Brokers take a pivotal role because of their powerful position within a network by virtue of their connection with many and powerful nodes, to use the language of social network analysis. Brokerage can be a mechanism for power-grabbing and control, deployed by state actors or other agents powerful in a more conventional sense, as is the case with Martin's "travel agents." However, brokerage may also be employed by "the grassroots" or even individuals. Judy Watson, the artist whose work is described by Kennedy and Graefenstein, can be seen as an effective memory-broker in that she makes use of her own travels and connective work to make the multidirectional (and transnational) memory of racism and colonialism visible to a broader audience.

\section{Conclusion}

The tension between local sites of memory and their transnational links and meanings is a consequence of the fact that many sites are both. This duality is not a contradiction, as we have seen through the lens of different theoretical treatments of the spatiality. The cases present in this volume demonstrate this clearly - showing the various ways in which transnationality is evoked, even as locality remains an important if not dominant frame. Evidence of transnational sharing or movement, however, does not always mean that a site is experienced by all as transnational or that such developments have transformed local or national memorialization practices outright. This is not to suggest that nothing is happening with such "places" (understood here as sites that have been made to seem static or still). The articles presented here demonstrate precisely that both places that are perceived as local and those that seem transnational are invested with agency that constructs their characteristics and that are meaningful to different actors. Moreover, the transnationality of a site not only can be latent and situational, making it conducive to being invoked and harnessed for different local, national, or global causes, but also at times seemingly vanishing from view.

As researchers, we are not only observing these phenomenon, we are participating in them. Björkdahl and Kappler (2019) reflect that "through multiple visits to our diagnostic sites, we were ourselves part of the transnationalization of memory. Our reading of those memorial sites as presented in this article is therefore not only a methodology, but also an ontological indication of how memory travels across local, national and international communities". While memory scholars are usually not so explicit about a "participant observer effect," I suspect that the normative commitments that drive academic interest in commemoration and transnationalism often make scholars into (intentional or inadvertent) agents of the transnationalization of memory. They become memory brokers, connecting local narratives, concepts, sites, and people with those elsewhere. Similarly, Barbara Törnquist-Plewa has recently also argued that "a memory investigator is potentially always a memory actor. Her or his research constitutes 
either direct or indirect intervention in memory work, either during data collection by personal intercession (...), or through the sheer communication of research results that puts the memories further on the move" (Törnquist-Plewa 2018, 310). Moreover, the type of spatiality - whether location, place, space, or scale - that is highlighted by a particular researcher is context-dependent and grounded in her positionality (Nicholls et al. 2013, 3). Transnational meaning in sites of memory may also be more recognizable to those whose lives are transnationally intertwined in other ways - and this is often the case for "memory professionals"-initiators, curators, memorial staff, intellectuals, and scholars. Reflecting on our own position and engagement as researchers can help us understand-and not overestimate - transnational relations as they shape public memory.

\section{References}

Augé, M. (2008). Non-places. An introduction to supermodernity. London: Verso.

Bachmann-Medick, D. (2009). Cultural turns. Neuorientierungen in den Kulturwissenschaften (Third ed.). Reinbek bei Hamburg: Rowohlt Verlag.

Berger, S., \& Seiffert, J. (2014). Erinnerungsorte - ein erfolgskonzept auf dem Prüfstand. In S. Berger \& J. Seiffert (Eds.), Erinnerungsorte. chancen, grenzen und perspektiven eines erfolgskonzeptes in den Kulturwissenschaften (pp. 11-36). Essen: Klartext Verlag.

Björkdahl, A., \& Kappler, S. (2017). Peacebuilding and spatial transformation: Peace, space and place. London: Routledge.

Björkdahl, A., \& Kappler, S. (2019). The creation of transnational memory spaces: Professionalization and commercialization. International Journal of Politics, Culture, and Society. https://doi.org/10.1007/s10767019-09328-5.

Bond, L., Craps, S., \& Vermeulen, P. (2016). Introduction: Memory on the move. In L. Bond, S. Craps, \& P. Vermeulen (Eds.), Memory unbound: Tracing the dynamics of memory studies. New York: Berghahn Publishers.

Cento Bull, A., \& Lauge Hansen, H. (2016). On agonistic memory. Memory Studies, 9(4), 390-404. https://doi. org/10.1177/1750698015615935.

de Cesari, C., \& Rigney, A. (Eds.). (2014). Transnational memory. Circulation, articulation, scales. Berlin: de Gruyter.

den Boer, P., Duchhardt, H., Kreis, G., \& Schmale, W. (Eds.). (2011). Europäische erinnerungsorte. Vol.1-3. Munich: De Gruyter Oldenbourg.

Erll, A. (2011). Travelling memory. Parallax, 17(4), 4-18.

Failler, A. (2018). Canada 150: exhibiting national memory at the Canadian museum for human rights. Citizenship Studies, 22(4), 358-380.

Gupta, A., \& Ferguson, J. (1997). Culture, power, place: Ethnography at the end of an era. In A. Gupta \& J. Ferguson (Eds.), Culture, power, place: Explorations in critical anthropology. Raleigh: Duke University Press.

Hahn, H. H., \& Traba, R. (Eds.). (2013). Deutsch-polnische erinnerungsorte. Vol.1-5. Paderborn: Ferdinand Schöningh Verlag.

Keightley, E., \& Pickering, M. (2017). Memory and the management of change: Repossessing the past. Basingstoke: Palgrave Macmillan.

Kennedy, R., \& Graefenstein, S. (2019). From the transnational to the intimate: Multidirectional memory, the holocaust and colonial violence in Australia and beyond. International Journal of Politics, Culture, and Society. https://doi.org/10.1007/s10767-019-09329-4.

Kennedy, R., \& Nugent, M. (2016). Scales of memory: Reflections on an emerging concept. Australian Humanities Review, 59(April/May).

Maier, C. S. (2007). "Being there": place, territory, and identity. In S. Benhabib, I. Shapiro, \& D. Petranovic (Eds.), Identities, affiliations, and allegiances. Cambridge: Cambridge University Press.

Nicholls, W., Miller, B., \& Beaumont, J. (2013). Introduction: Conceptualizing the spatialities of social movements. In W. Nicholls, B. Miller, \& J. Beaumont (Eds.), Spaces of contention. spatialities and social movements. Farnam: Ashgate Publishing.

Nora, P. (1996). General introduction: Between memory and history (A. Goldhammer, Trans.). In P. Nora \& L. D. Kritzman (Eds.), Realms of memory (English ed., Vol. 1). New York: Columbia University Press. 
Pirker, P., Kramer, J., \& Lichtenwagner, M. (2019). Transnational memory spaces in the making: World war II and holocaust remembrance in Vienna. International Journal of Politics, Culture, and Society. https://oi. org/10.1007/s10767-019-09331-w.

Radstone, S. (2011). What place is this? Transcultural memory and the locations of memory studies. Parallax, 17(4), 109-123.

Rothberg, M. (2014). Multidirectional memory in migratory settings: The case of post-holoaust Germany. In C. de Cesari \& A. Rigney (Eds.), Transnational memory: Circulation, articulation, scales. Berlin: de Gruyter Press.

Tilly, C. (2001). Mechanisms in political processes. Annual Review of Political Science, 4, 21-41.

Törnquist-Plewa, B. (2018). The transnational dynamics of local remembrance: The Jewish past in a former shtetl in Poland. Memory Studies, 11(3), 301-314.

Tuan, Y.-F. (1977). Space and place. The perspective of experience. Minneapolis: University of Minnesota Press. Wüstenberg, J. (forthcoming). Agency and practice in the making of transnational memory politics. In J. Wüstenberg \& a. Sierp (Eds.), Agency in Transnational Memory Politics. New York: Berghahn Publishers. Wüstenberg, J. (2017). Civil society and memory in postwar Germany. Cambridge: Cambridge University Press.

Publisher's Note Springer Nature remains neutral with regard to jurisdictional claims in published maps and institutional affiliations. 